\title{
Effect of the Various Processed Food of the Far North Cameroon on the Glycemic Index
}

\author{
Benoît B. Koubala1 ${ }^{*}$, Germain Kansci², Abdoulaye N. P. Fifen ${ }^{1}$, Angèle I. Ngoufack ${ }^{1}$, \\ Yvette C. M. Dadjeu ${ }^{1}$ \\ ${ }^{1}$ Department of Life and Earth Sciences, University of Maroua, Maroua, Cameroon \\ ${ }^{2}$ Department of Biochemistry, University of Yaoundé I, Yaoundé, Cameroon \\ Email: ${ }^{*}$ bkoubala@yahoo.fr
}

Received 5 January 2014; revised 5 February 2014; accepted 13 February 2014

Copyright (C) 2014 by authors and Scientific Research Publishing Inc.

This work is licensed under the Creative Commons Attribution International License (CC BY). http://creativecommons.org/licenses/by/4.0/

(c) (i) Open Access

\begin{abstract}
Metabolic Syndrome (MS) has reached a pandemic proportion and has an impact on the incidence and severity of cardiovascular pathologies. This study was conducted to evaluate the effect of different processed food commonly consumed in Maroua (Far North Region, Cameroon) on the Glycemic Index (GI). To ameliorate the follow up of MS and population's nutrition education, a survey was conducted among 200 families. The ten most consumed meals were selected after a food survey among 200 families. The meals were mostly made of a vegetable soup associated to a high carbohydrate staple. Vegetables and cereals were processed according to the food survey results. Then, a food tolerance test was performed on 30 male volunteers living in the same region. Among them, 12 were selected with an average age of 28.25 and a mean BMI of 19.63. They were studied on separate occasions in the morning after an overnight fast. After fasting, blood glucose was taken before and $(15,30,45,60,90$ and 120 minutes) after eating a test meal compared to sucrose and glucose solution (33.33\%) used as reference. Glycemic response curves were used to calculate the gi of each meal. Results show that GI of the tested meals varied significantly $(p<0.05)$ between 20 and 79. Red millet porridge with kelenkelen-beans (Cochorus oletorius-Vigna unguiculata) sauce and red millet porridge with kelenkelen-peanut (Cochorus oletorius-Arachis hypogea) sauce exhibited the lowest GI. The highest GI was observed in corn porridge associated with fresh okra (Hibuscus esculentus) or with tasba (Cassia tora)-okra-beans sauce.
\end{abstract}

\section{Keywords}

Food Processing; Meals; Glycemic Index; Glycemia; Far North Cameroon

\footnotetext{
${ }^{*}$ Corresponding author.
} 


\section{Introduction}

The Glycemic index (GI) introduced by [1] is the capacity of a carbohydrates rich food to raise the blood glucose concentration [2]. It is a criteria of classification of carbohydrates food, based on their effects on the postprandial glycemia. More a food has an index close to 100, more it is said to be "fast". Contrary, a food exhibiting an index close to 0 is said to be "slow" [3]. The postprandial glycemia of a food is deeply affected by the intrinsic and extrinsic factors [4]. Currently the GI is of a considerable progress in nutrition because it is a physiological and integrated parameter that defines objectively, the glycemia modifications consecutive to an ingestion of a food. So we are not more interested in the chemical composition of the food, but in the biological response consecutive to its ingestion. By this, GI appears to be the most reliable way to evaluate the kinetics of the absorption of glucose contained in a food. His knowledge, current dietary recommendations in line to select and adapt food choices based on the needs and the physiological condition of the body would be beneficial not only for the public but for people with metabolic syndrome (MS) [5].

These anomalies (obesity, diabetes, dyslipidaemia and hypertension) are often moderate carbohydrate origin, or vascular lipid associated with being overweight, which will act in synergy, cause of type 2 diabetes and predispose to atherosclerosis and its clinical events. Its prevalence depends on the definition, year of study, age and sex of the population [6], which complicates analyses between countries and continents [7]. Type 2 diabetes and obesity are both major factors in the recent development of MS [8]. Diabetes appears to be an important public health problem in the world [9] [10]. In Cameroon, the statistics are equally alarming when there is an increase of the prevalence from 1.5\% to 13\% between 2006 and 2008 [11]. Depending on the risk level of the MS, a more or less aggressive pharmacotherapy is initiated through many scientific researches. But due to its high cost, its counter-indications and adverse side effects, lifestyle (nutrition therapy and physical activity) constitute the cornerstone [8] [12] [13] to prevent or treat the SM. This is why the American Diabetes Association (ADA) recommends low GI foods as opposed to high GI foods that seem to be a risk factor for obesity and cardiovascular disease (CVD). It has been shown that fruits, vegetables and legumes are low GI foods whereas cereals and sugars are high GI foods [14]. These low GI foods are mainly composed of non-nutritive biologically active components (tannins, phytic acid and protease inhibitors) and bioactive complex carbohydrate which are involved in the prevention of SM [15]-[17]. To maintain these benefit effect, we have to define a good processing method to produce the food that they are derived from. Bahado-Singh et al. [18] showed that with sweet potatoes, boiling is the best to minimize postprandial blood glucose spikes compare to roasting, baking and frying cooking method. Nayak et al. [19] even noticed that food processing (domestic boiling, baking, microwave cooking, oven cooking, extrusion and frying) affect the degrees of gelatinization and crystallinity of starch in potato. According to the process used, the obtained starch can be more resistant or digestible. It have been also noticed an influence of processing on dietary fiber and tannin of pearl millet [20]. Most of studies have been done on the GI of individual food and mostly European food [14] [21]. A meal is a complex mixture of compounds which makes difficult the determination of the GI. However, the GI of some mixed food has been established [22]. In Cameroon, till now, only the GI of some south dishes is well known. For example, Koki beans and cassava with a serving portion of 122 gramme exhibits a GI of 52 [22] [23]. But the GI of the most common northern Cameroonian dishes has not yet been established. The northern part of Cameroon has three regions. Maroua town is the city of the Far North Region.

According to the Central Office of Registration and Population Studies of Cameroon, Maroua exhibit about 300,000 inhabitants which represent $11 \%$ of the Far north region population. The economy of Maroua city is structured around small urban subsistence farming. The main production (sorghum, rice, cattle, sheep, poultry...) comes from surrounding villages and towns. As Maroua is close to major tourist attractions as well as Nigeria and Chad, the hotel industry is well developed. Most of manufactured products are from Nigeria and China. The cotton development company (SODECOTON) is also a major economic hub with its shelling and oil factories which respectively produce fiber, oil and crab. These factories also employ a large workforce. We meet banks and micro-credit structures which are the main sources of funding for economic activities.

In order to contribute to a better food supply of Cameroonians in general and those with metabolic syndrome in particular, the objective of this work is to determine the GI of some processed foods commonly consumed in the city of Maroua (Far North of Cameroon). 


\section{Material and Methods}

\subsection{Preparation of Food Dishes}

From Mai to June of 2012, a dietary survey was conducted among 200 families living in the city Maroua (Far North of Cameroon) to obtain information on: commonly consumed meals, frequency of consumption, the method of cooking and the common name of the main ingredients used. This survey was conducted after obtaining an administrative authorization from the tree sub-prefects of the city. Among 33 identified meals, 10 were selected because of their high consumption frequencies (Table 1). As previously observed by Byars [24] on the nutritional habit of African American, the analysis of the selected meals showed a high consumption frequency of greens, grains and legumes. In July of the same year of dietary survey, foodstuff were purchased in the different markets of Maroua and then returned to the laboratory where they were processed. Maize with and without bran (Zea mays) and millet (Sorghum bicolor) were sorted, washed and dried before being sent to the mill to get flour which was sieved.

The meals were prepared each morning $(7 \mathrm{~h}) 30$ minutes before the arrival of the selected volunteers. As described by Kurauchi [25], maize and miller flour was used to prepare corn and millet porridges (commonly called fufu or couscous) with an average dry matter content of $25 \%$. About $1500 \mathrm{ml}$ of tap water was left boiling in a pot. Slurry was formed by mixing $100 \mathrm{~g}$ of flour with $250 \mathrm{ml}$ of water. The obtained slurry was poor into the boiling water and left cooked for 5 minutes. Another $100 \mathrm{~g}$ of flour was added into the pot and the mixture was left cooked for 15 minutes with constantly stirring. A serving portion (260 - $280 \mathrm{~g}$ ) of porridges was taking away from the pot with a soup ladle greased with oil. Each portion was left cooled onto a serving plate before eating. In the case of rice (Oriza orifa), $500 \mathrm{~g}$ have previously been boiled in 2 litters of tap water for 25 minutes. The cooked rice was mash in order to be homogenized. A soup ladle was also used to form the eating portion (260 g) (25\% of dry matter).

Sauces consisted of vegetables such as Folléré leaves (Hibuscus sabdariffa), Kelenkelen leaves (Cochorus oletorius), Okra fruit (Hibuscus esculentus), Doubao leaves (Allium digitata), Onion leaves (Allium cepas) and Tasba leaves (Cassia tora). We had also cowpea beans (Vigna unguiculata), peanut, meat or fish associated with salt and some spices.

The average dry matter content of these sauces was $15 \%$.

Table 1. Consumption rate (\%) and glycemic index (GI) of the test meals.

\begin{tabular}{cccccc}
\hline & Test meals & & \multicolumn{2}{c}{ Serving portion (g) } \\
\hline Soup & Carbohydrate staples & $\begin{array}{c}\text { Coded meal and } \\
\text { consumption rate (\%) }\end{array}$ & Soup (15\%) & Staple (25\%) \\
\hline Fresh Okra & Fufu corn without bran & FO/CWtB (9.4) & 100 & 260 & $67.55 \pm 5.75^{\mathrm{b}}$ \\
Boko & Fufu corn with bran & Bo/CWB (8.07) & 100 & 280 & $44.05 \pm 4.65^{\mathrm{cd}}$ \\
Tasba-Okra-Beans & Fufu corn with bran & TOB/CWB (7.7) & 100 & 280 & $78.74 \pm 3.94^{\mathrm{a}}$ \\
Doubao-Peanut-Beans & Fufu rice & DPB/Ri (7.4) & 100 & 260 & $47.93 \pm 4.43^{\mathrm{c}}$ \\
Foléré-Peanut & Fufu yellow sorghum & FP/YS (8.07) & 100 & 275 & $37.65 \pm 3.71^{\mathrm{de}}$ \\
Guiligandja-Peanut & Fufu yellow sorghum & GP/YS (7.03) & 100 & 275 & $45.63 \pm 4.66^{\mathrm{d}}$ \\
Dried Okra & Fufu corn without bran & DO/CWtB (10.03) & 100 & 260 & $35.18 \pm 4.36^{\mathrm{de}}$ \\
Onion leaves-Peanut-Beans & Fufu rice & OPB/Ri (11.7) & 100 & 260 & $35.37 \pm 3.87^{\mathrm{de}}$ \\
Kelenkelen-Peanut & Fufu red millet & KP/RM (7.8) & 100 & 280 & $31.52 \pm 4.42^{\mathrm{e}}$ \\
Kelenkelen-Beans & Fufu red millet & KB/RM (9.1) & 100 & 280 & $19.91 \pm 3.20^{\mathrm{f}}$ \\
& Sucrose solution (33.33\%) & & $150(\mathrm{ml})$ & $50.98 \pm 4.20^{\mathrm{c}}$ \\
\hline
\end{tabular}

Values of IG are mean from six different measurements \pm standard deviation. Values followed by different superscripts are significantly different (p < 0.05). Scientific name of the plant source of the different greens or vegetables used: Okra (fruit) = Hibuscus esculentus, Boko (leaves) = Alium digitata, Tasba (leaves) = Cassia tora, Beans (seed) = Vigna unguiculata, Doubao (leaves) = Alium digitata, Folléré (leaves) = Hibiscus sabdariffa, Guiligandja (leaves) = Moringa olifera, Kelenkelen (leaves) = Cochorus oletorius . 


\subsection{Screening and Selection of the Volunteers}

After obtaining permission from the Regional Delegate of Health, volunteers were invited. The study was conducted in strict compliance with the rights and integrity of man. The objectives, protocol and the importance of the study were explained to the participators. Subjects who agreed to participate in the study signed an informed consent form.30 young male fasting and aging between 25 and 30 years were invited. They underwent a screening for obesity, diabetes and hypertension.

They were then observed whiting a week during which their anthropometric parameters, blood pressure and blood glucose were measured. During the observation period were excluded from the study: volunteers with digestive problems (chronic diarrhoea, constipation, flatulence), on medication, allergies and malnutrition, those with pancreatic dysfunction and chronic patients (overweight or obesity, hyperglycemia or diabetes, hypertension). At the end of the observation period, 12 subjects were selected for the study. They had an average age of 28.25 and a BMI of 19.63.

\subsection{Ingestion of Test Meals and Evaluation Glycemia}

The test meals were studied in comparison with two simple foods: sucrose solution (33.33\%) used as a control and a glucose solution (33.33\%) used as the reference food. For each day, the subjects (12) were divided into 2 groups of 6 (1 test group and one control group). The reference group drank $150 \mathrm{ml}$ of either glucose or sucrose solution. For the test group, cooked high carbohydrate staples (containing $50 \mathrm{~g}$ of polysaccharides) were consumed with $100 \mathrm{~g}$ of different sauces (Table 1). Test meals were served with drinking water in all occasions. Glycemic response to the various meals was measured using an experimental design described in greater detail previously by Wilson et al. [16]. After 10 - 12 hours of fasting blood glucose of all subjects was measured and several times (15, 30, 45, 60, 75, 90 and 120 minutes) after food intake. To perform this, the fingertips of the subjects were disinfected using ethanol (90\%). With a sterile needle, a gently pressure was applied to the pricked finger and a drop of blood was collected for the determination of blood glucose concentration. For this purpose a glucometer (Accu-checkR Aviva) was used according to glucose oxidase method described by Trinder [26].

\subsection{Determination of the Glycemic Index (GI) of the Meals}

From each subject's blood glucose, an average value of glycemia was calculated for each group at different times. This allowed tracing glycemic response curves over time $($ Glycemia $=\mathrm{f}(\mathrm{t}))$. From a baseline, incremental surface area below the curve was calculated. The GI of each meal was calculated by dividing the incremental area under the curve of the test meal by the reference food and the result is multiplied by 100 [27].

$$
\mathrm{GI}(\%)=[(\text { Incremental area of the test food }) /(\text { Incremental area of Glucose })] \times 100
$$

\subsection{Statistical Analysis}

The means and standard deviations of the data were calculated. They were then analysed by the analysis of variance (ANOVA) and significance judged at $\mathrm{p}<0.05$ using SPSS (Statistical Package of Social Science) software version 10.1. equations.

\section{Results and Discussion}

\subsection{Effect of the Different Meals on the Blood Glucose Response}

Figure 1 shows the different glycemic responses (g/L) obtained after ingestion of various meals. An overall observation is an increase in blood sugar drops after a certain time, which implies a regulatory mechanism provided by the liver [14]. Contrary to the other foods, glucose which is used as reference shows a strong increase in blood glucose reaching $1.43 \mathrm{~g} / \mathrm{L} 30$ minutes after ingestion. This simple molecule does not need to be hydrolysed before being absorbed. We also note that the different response curves are not uniform compared to that of glucose and sucrose. Although simpler than the various meals, sucrose has a low glycemic response. This low response will be related to its composition. Sucrose is a diholoside consisting of glucose and fructose, and must be hydrolysed before being assimilated [28]. Among the 10 selected meals, 5 lead to a rapid glycemic response greater than or equal to $1.1 \mathrm{~g} / \mathrm{L} 30$ minutes after ingestion (Figure 1). This is fufu corn without bran with fresh 

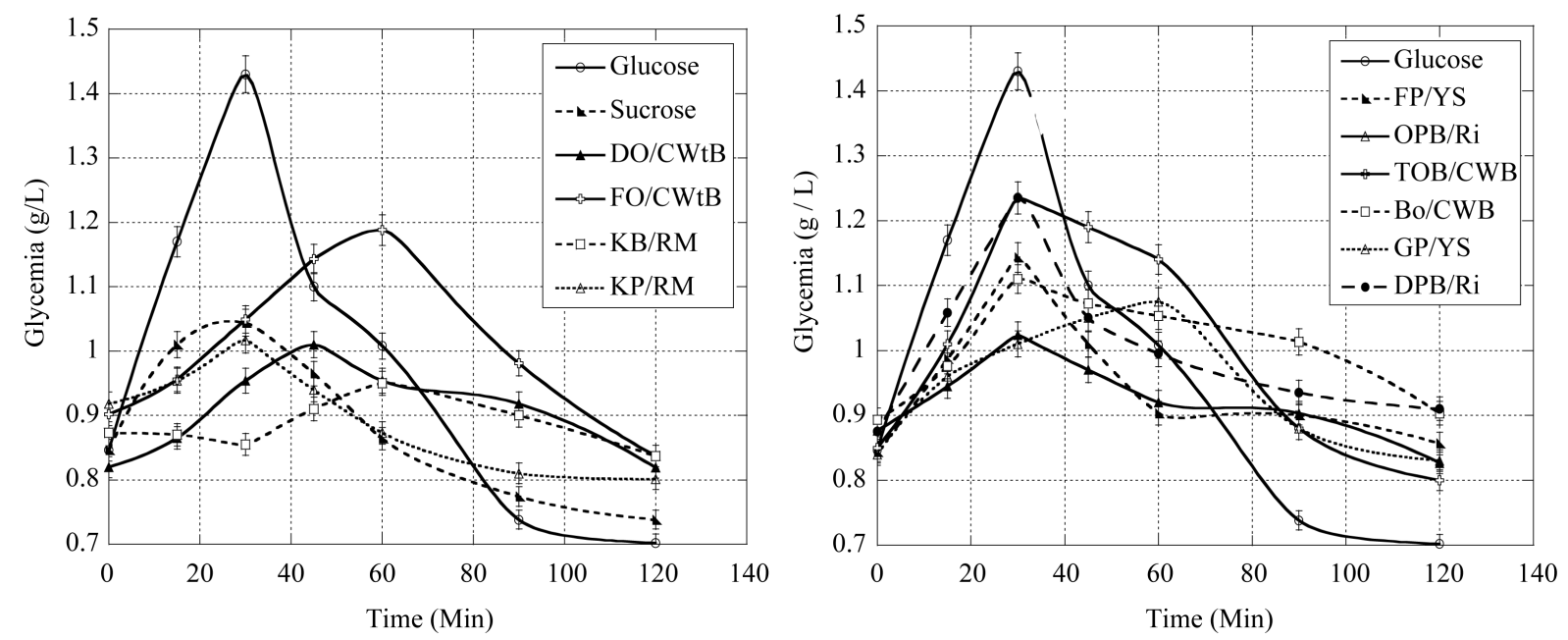

Figure 1. Variation of blood glucose concentration (g/l) of subjects after consumption of various meals. The meals are composed of some high carbohydrate staples (corn, sorghum, millet and rice) associated with some soups. FO/CWtB = Fresh Okra/Fufu Corn without bran; Bo/CWB = Boko/Fufu corn with bran; TOB/CWB = Tasba-Okra-Beans/Fufu corn with bran; DPB/Ri = Doubao-Peanut-Beans/Fufu rice; FP/YS = Foléré-Peanut/Fufu yellow sorghum; GP/YS = GuiligandjaPeanut/Fufu yellow sorghum; DO/CWtB = Dried Okra/Fufu corn without bran; OPB/Ri = Onion leaves-Peanut-Beans/Fufu rice; KP/RM = Kelenkelen-Peanut/Fufu red millet; KB/RM = Kelenkelen-Beans/Fufu red millet.

okra sauce (FO/CWtB), fufu corn with bran accompanied with Boko sauce (Bo/CWB), fufu corn with bran associated with Tasba-okra-beans sauce (TO/CWB), fufu rice with Doubao-peanut-beans sauce (DPB/Ri) and fufu yellow sorghum with Folléré-peanut sauce (FP/YS). If glycemic responses increase after ingestion of the various meals, this is not the case of Kelenkelen-beans sauce/fufu red millet (KB/RM) of which glycemic response stays at fasting state for 30 minutes before a slight increasing $(<1 \mathrm{~g} / \mathrm{L})$.

\subsubsection{Effect of the Sauces}

Consumption of Kelenkelen-peanut sauce with fufu red millet (KP/RM) causes a rapid rise in postprandial glucose, but the rising rate is lower than those of glucose and sucrose. The reducing effect of Kelenkelen-beans sauce on blood sugar could be explained by the complexity of it constitutional carbohydrates which are slowly digested. In addition there could be anti-nutritional compounds that limit the absorption of glucose. The Kelenkelen-beans and Kelenkelen-peanut sauces consumed with fufu red millet differed by the presence of beans in the first and peanut butter in the second sauce. The slight increase of glucose response induced Kelenkelen-beans can be due to the presence of proteins, dietary fiber and antinutrients in the beans. Dimodi [29] showed that beans proteins inhibit amylase activity, which contributes to reduce the glycemic response. Similarly, Thompson et al. [30] and Jenkins et al. [31] respectively noticed that dietary fiber and antinutrients significantly reduce the glycemic response.

We also observe a highly significant difference $(\mathrm{p}<0.05)$ between the glucose response curves obtained with fresh okra sauce and with dried okra sauce both consumed with fufu corn without bran (Figure 1). The composition of these two sauces differs by the state (dried and fresh) of the greens used. The low increase of blood glucose induced by dried okra is due to the high concentration of resistant starch playing the role of dietary fiber [32]. These results are in agreement with those of Fernandez [33] who showed that the more the dietary fiber in a meal, more glycemic response is low. According to Ndjouenkeu et al. [34] hydrocolloids found in okra exhibit thickening property as dietary fiber.

Compare to Boko sauce associated with fufu corn (whole grain), results showed a rapid rise of postprandial glycemia after eating Tasba-okra-beans sauce accompanied with the same fufu corn. Glycemic peaks of these two dishes appear 30 minutes after ingestion, but the rate of glucose absorption was lower that containing Tas$b a$-okra-beans sauce. This shows up the presence of dietary fiber in okra and bean but also that of anti-nutrients and proteins in beans which reduce the postprandial glycemic response [29] [30] [35].

After consumption of Doubao-peanut-beans sauce with fufu rice ball, blood sugar rises rapidly (peak after 30 min) with a rising rate than those obtained with glucose, sucrose and onion leaves-beans-peanut sauce eaten with 
fufu rice (Figure 1). As beans, onion leaves contain compounds that would affect negatively the rate of digestion of starch in rice. This could be due to the presence of quercitin (13 - $20 \mathrm{mg} / 100 \mathrm{~g})$ in onion [36]. Quercitin is an antioxidant belonging to the family of polyphenols. Thomson et al. [30] have shown that polyphenols affect the glycemic response by interaction with starch; reducing its digestion rate. The Folléré-peanut sauce accompanied by fufu yellow millet causes a rapid rise in blood glucose which falls immediately after. However, Guiligandja-peanut sauce accompanied by the same fufu causes a slow and gradual rise in glycemia which the peak appears only 60 min after consumption. Differences of glycemia are derived from the biochemical composition of these two greens (Folléré and Guiligandja) used to prepared the two sauces. The low and slow glycemic response observed after ingestion of Guiligandja sauce, can be explained by its high antioxidants (flavonoids and polyphenols) content as shown by Suzuky et al. [37].

\subsubsection{Effect of the High Carbohydrate Staples}

The different fufu were prepared with corn without bran, corn with bran, rice, red millet and yellow millet. In Figure 1, we observe that fufu corn (with or without bran) exhibits the highest glycemic response. This is followed by rice, fufu red millet being the staple which exhibit the lowest glycemic response. This suggests that starch in the maize and rice are more available than that found in millet. Millet could be rich in resistant starch. It have been reported that the energy value $(4.2 \mathrm{kcal} / \mathrm{g})$ of one gram of completely digested starch is two time more than that of one gram of completely fermentable resistant starch (2 kcal/g) [38].

\subsection{Glycemic Index (GI) of the Different Meals Consumed in the Fare-North of Cameroon}

Table 1 shows that there are significant differences $(\mathrm{p}<0.05)$ between the GI of the eaten meals $(20-68)$. These GI values explain the low prevalence of SM observed in Maroua (far north) compared to that observed in southern Cameroon. Kelenkelen-beans sauce associated with fufu red millet exhibits the lowest value of GI meanwhile fresh okra sauce accompanied with fufu corn without bran shows the highest value of GI. We also note that the staple prepared with corn have the highest GI unlike those made with millet, rice and sorghum. According to Brand-Miller [14] and Okafor [39], rice has a GI situated around 60 and the corn exhibits 77 [14]. The high value of GI observed with fufu corn could be due to its high digestible carbohydrates content. In agreement with Bahado-Singh et al. [18], the processing method can also explain these differences. The glycemic index of sweet potatoes significantly varies with the method of preparation (roasting, baking, frying, or boiling). We can also think of the various ingredients used in sauces associated with these two carbohydrate rich staples. Beans and peanuts are foods that have significant quantities of carbohydrate. According to Okafor [39] baked beans exhibit a GI of 61. The GI obtained after ingestion of sucrose is slightly lower than the value (59) of GI obtained by Brand-Miller [14].

Regarding the different sauces, Kelenkelen, onion leaves and beans have a reducing effect on the GI of the meal. It has been shown that fibres rich foods are low glycemic index foods and are more slowly digested in vitro [31]. Among these foods we have: dried legumes, peas, beans and lentils. This is then the combined effect of dietary fiber, antinutrients and protein of beans which explains the low glycemic response induced by meals containing Kelenkelen and beans. We recommend to the diabetics the consumption of fufu red millet associated with Kelenkelen-beans sauce. Onimawo et al. [40] said steamed cakes from Bambara nut (okpa) is a better diet for the diabetics. that recommended to Over a six-year period study, Jenkins et al. [31] noticed a negative correlation and a net evidence between low-index diets glycemic and type 2 diabetes.

The physicochemical properties of these meals should be established specially the soluble sugars, total carbohydrates, proteins, phenolic compounds, antinutrient compounds and fibres content. After that their energy value should also be evaluated. These analyses will move out the net correlation existing between the IG and the amount of the different nutrient present in the eaten meal. After that, a best formulation for a particular SM statute can be formulated.

\section{Conclusion}

This study is the first to report variations in the glycemic index and blood glucose responses among commonly consumed meals in the far north region of Cameroon. The objective of this work was to determine the GI of food commonly eaten in the city of Maroua (far north, Cameroon). It appears that the population mostly eats fufu made with sorghum, maize or millet flour accompanied with sauces of okra fruit, Kelenkelen leaves, onion 
leaves, Tasba leaves and Folléré leaves containing peanut, meat, beans or dried fished. GI of the ten most consumed meals varied between 20 and 79. Kelenkelen-beans sauce associated with fufu red millet is the lowest GI meal which can be recommended to diabetics. The glycemic table and pyramid of those meals that have been studied will be used to improve the nutrition care of the population.

\section{Aknowledgements}

The first author expresses sincere thanks to the population of Maroua Town for facilitating the dietary survey.

\section{References}

[1] Jenkins, D.J.A., Wolever, T.M.S., Taylor, R.H., et al. (1981) Glycemic Index of Foods: A Physiological Basis for Carbohydrate Exchange. The American Journal of Clinical Nutrition, 34, 362-366.

[2] Chlupa, R., Bartek, J., Řezničkova, M., et al. (2004) Determination of the Glycemic Index of Selected Foods (White Bread and Cereal Bars) in Healthy Persons. Biomedical Papers, 148, 17-25. http://dx.doi.org/10.5507/bp.2004.003

[3] Meri, R. (2010) The Glycemic Index Diet for Dummies. Wiley Publishing, Inc., Indianapolis.

[4] Pi-Sunyer, F.X. (2002) Glycemic Index and Disease. The American Journal of Clinical Nutrition, 76, 290S-298S.

[5] Rizkalla, S.W., Bellisle, F. and Slama, G. (2002) Health Benefits of Low Glycaemic Index Foods, Such as Pulses, in Diabetic Patients and Healthy Individuals. British Journal of Nutrition, 88, 255-262. http://dx.doi.org/10.1079/BJN2002715

[6] Reaven, G.M. (1988) Role of Insulin Resistance in Human Disease. Diabetes, 37, 1595-1607. http://dx.doi.org/10.2337/diab.37.12.1595

[7] Cameron, A.J., Shaw, J.E. and Zimmet, P.Z. (2004) The Metabolic Syndrome: Prevalence in Worlwide Populations. Endocrinology and Metabolism Clinics of North America, 33, 351-375. http://dx.doi.org/10.1016/j.ecl.2004.03.005

[8] Bonnet, F. and Laville, M. (2005) Le Syndrome Métabolique: Définition, Epidémiologie, Complications. Spectra Biologie, 145, 27-29.

[9] WHO (2005) Prevention of Blindness from Diabetes Mellitus. Report of a WHO Consultation. WHO, Geneva.

[10] Foster, A., Gilbert, C. and Johnson, G. (2008) Changing Patterns in Global Blindness: 1988-2008. Community Eye Health Journal, 21, 37-39.

[11] Fezeu, L., Balkau, B., Kengne, A.P., et al. (2007) Metabolic Syndrome in a Sub-Saharan African Setting: Central Obesity May Be the Key Determinant. Atherosclerosis, 193, 70-76. http://dx.doi.org/10.1016/j.atherosclerosis.2006.08.037

[12] NCEP (National Cholesterol Education Program) (2001) Expert Panel on Detection, Evaluation and Treatment of High Blood Cholesterol in Adults. Executive Summary of the Third Report on the National Cholesterol Education Program, The Journal of the American Medical Association, 285, 2486-2497. http://dx.doi.org/10.1001/jama.285.19.2486

[13] Lindholm, L.H., Ibsen, H., Dahlf, B. et al. (2002) Cardiovascular Morbidity and Mortality in Patients with Diabetes in the Losartan Intervention for Endpoint Reduction in Hypertension Study (Life): A Randomised Trial against Atenolol. Lancet, 359, 1004-1010. http://dx.doi.org/10.1016/S0140-6736(02)08090-X

[14] Brand-Miller, J. (2002) Carbohydrates. In: Mann, J. and Truswell, A.S., Eds., Essentials of Human Nutrition, Oxford University Press, Oxford, 11-29.

[15] Salwa, M.E., Maha, I.A.M., Hamed, I.M., et al. (2012) Dietary Therapy of Obesity: Effect on Some Hormonal and Biochemical Blood Indices. African Journal of Food, Agriculture, Nutrition and Development, 12, 6881-6896.

[16] Wilson, T., Singh, A.P., Vorsa, N., et al. (2008) Human Glycemic Response and Phenolic Content of Unsweetened Cranberry Juice. Journal of Medicinal Food, 11, 46-54. http://dx.doi.org/10.1089/jmf.2007.531

[17] Singh, J. and Basu, P.S. (2012) Non-Nutritive Bioactive Compounds in Pulses and Their Impact on Human Health: An Overview. Food and Nutrition Sciences, 3, 1664-1672. http://dx.doi.org/10.4236/fns.2012.312218

[18] Bahado-Singh, P.S., Riley, C.K., Wheatley, A.O. and Lowe, H.I.C. (2011) Relationship between Processing Method and the Glycemic Indices of Ten Sweet Potato (Ipomoea batatas) Cultivars Commonly Consumed in Jamaica. Journal of Nutrition and Metabolism, 2011, 6 p. http://dx.doi.org/10.1155/2011/584832

[19] Nayak, B., De J. Berrios, J. and Tang, J. (2014) Impact of Food Processing on the Glycemic Index (GI) of Potato Products. Food Research International, 56, 35-46. http://dx.doi.org/10.1016/j.foodres.2013.12.020

[20] Pushparaj, F.S. and Urooj, A. (2011) Influence of Processing on Dietary Fiber, Tannin and in Vitro Protein Digestibility of Pearl Millet. Food and Nutrition Sciences, 2, 895-900. http://dx.doi.org/10.4236/fns.2011.28122

[21] Foster-Powell, K., Holt, S.H.A. and Brand-Miller, J.C. (2002) International Table of Tlycemic Index and Glycemic Load Values: 2002. The American Journal of Clinical Nutrition, 76, 5-56. 
[22] Atkinson, F.S., Foster-Powell, K. and Brand-Miller, J.C. (2008) International Tables of Glycemic Index and Glycemic Load Values: 2008. Diabetes Care, 31, 2281-2283. http://dx.doi.org/10.2337/dc08-1239

[23] Momha, (2009) Contribution à l'Etude de l'Index Glycémique de Quelques Aliments Consommés au Cameroun: Elaboration d'une Table et d’une Pyramide d’Index Glycémique. Mémoire de Master, Université de Yaoundé I, 40 p.

[24] Byars, D. (1996) Traditional African American Foods and African Americans. Agriculture and Human Value, 13, 74-78. http://dx.doi.org/10.1007/BF01538229

[25] Kurauchi, N. (2009) Pearl Millet. In: Japan Association for International Collaboration of Agriculture and Forestry, Ed., Minor Cereals Millets in Niger, 39-58.

[26] Trinder, P. (1969) Determination of Glucose in Blood Using Glucose Oxidase with an Alternative Oxygen Acceptor. Annals of Clinical Biochemistry, 6, 24-27. http://dx.doi.org/10.1177/000456326900600108

[27] FAO, (1997) Carbohydrates in Human Nutrition: Report of a Joint FAO/WHO Expert Consultation. FAO Food and Nutrition Paper-66, Rome, 14-18.

[28] Mann, J.I., De Leeuw, I., Hermansen, K., et al. (2004) Evidence-Based Nutritional Approaches to the Treatment and Prevention of Diabetes Mellitus. Nutrition, Metabolism and Cardiovascular Diseases, 14, 373-394. http://dx.doi.org/10.1016/S0939-4753(04)80028-0

[29] Dimodi, H.T. (2008) Evaluation de l’Activité Anti-Amylasique des Légumineuses Consommées au Cameroun: Etude Comparative Entre Vigna subterranea, Vigna unguiculata et Phaseolus vulgaris. Mémoire Soutenu en Vue de l’Obtention du Diplôme d'Etudes Approfondies (DEA) de Biochimie, Université de Yaoundé I, 57 p.

[30] Thompson, L.U., Button, C.L. and Jenkins, D.J.A. (1987) Phytic Acid and Calcium Affect the in vitro Rate of Navy Bean Starch Digestion and Blood Glucose Response in Humans. The American Journal of Clinical Nutrition, 46, 467-473.

[31] Jenkins, D.J.A., Jenkins, A.L., Kendall, C.W.C., et al. (2001) Dietary Fiber, Carbohydrate Metabolism and Chronic Disease. In: McCleary, B.V. and Prosky, L., Eds., Advance Dietary Fiber Technology, Blackwell Science Ltd., London, 162-167.

[32] De Vries, J.W. (2003) On Defining Dietary Fibre. Proceedings of the Nutrition Society, 62, 37-43. http://dx.doi.org/10.1079/PNS2002234

[33] Fernandez, M.L. (2001) Soluble Fiber and Nondigestible Carbohydrate Effect on Plasma Lipids and Cardiovascular Risk. Current Opinion in Lipidology, 12, 35-40. http://dx.doi.org/10.1097/00041433-200102000-00007

[34] Ndjouenkeu, R., Akingbala, J.O. and Oguntimein, G.B. (1997) Emulsifying Properties of Three African Food Hydrocolloids: Okra (Hibiscus esculentus), Dika Nut (Irvingia gabonensis) and Khan (Belschmiedia sp.). Plant Foods for Human Nutrition, 51, 245-255. http://dx.doi.org/10.1023/A:1007917608137

[35] Rea, R.L., Thompson, L.U. and Jenkins, D.J.A. (1985) Lectins in Foods and Their Relation to Starch Digestibility. Nutrition Research, 5, 919-929. http://dx.doi.org/10.1016/S0271-5317(85)80105-6

[36] Huang, Z., Wang, B., Eaves, D.H., Shikany, J.M. and Pace, R.D. (2007) Phenolic Compound Profile of Selected Vegetables Frequently Consumed by African American in the Southeast United States. Food Chemistry, 103, 1395-1402. http://dx.doi.org/10.1016/j.foodchem.2006.10.077

[37] Suzuki, Y., Ishihara, M., Segami, T. and Ito, M. (1998) Anti-Ulcer Effects of Antioxidant, Quercetin, $\alpha$-Tocopherol, Nifedipine and Tetracycline in Rats. Japanese Journal of Pharmcology, 78, 435-441. http://dx.doi.org/10.1254/jip.78.435

[38] Liversey, G. (1994) Energy Value of Resistant Starch. In: Asp, N.-G., van Amelsvoort, J.M.M. and Hautvast, J.G.A.J., Eds., Proceedings of the Concluding Plenary Meeting of Euresta, Euresta, 56-62.

[39] Okafor, E.N., Onyechi, I., Ozumba, A.U., et al. (2011) Glycemic Index of Some Commonly Consumed Staples in Nigeria. Pakistan Journal of Nutrition, 10, 1058-1060. http://dx.doi.org/10.3923/pjn.2011.1058.1060

[40] Onimawo, I.A., Ijeh, I., Ukoha, U. and Nwachukwu, G.T. (2007) Determination of the Glycemic Index of Steamed Cakes Using Two Different Legumes Bambara Nut (Vigna subterranean) and Cowpea (Vigina unguiculata). African Journal of Biochemistry Research, 1, 142-147. 